\title{
Outline-based geometric morphometric analysis to identify two Anopheles and three Culex mosquitoes in Thailand
}

\author{
TANAWAT CHAIPHONGPACHARA \\ Department of Public Health and Health Promotion, College of Allied Health Science, Suan Sunandha Rajabhat University, Samut Songkhram 75000, \\ Thailand. Tel./fax.: +66-835-865775, email: tanawat.ch@ ssru.ac.th
}

Manuscript received: 29 May 2019. Revision accepted: 14 June 2019

\begin{abstract}
Chaiphongpachara T. 2019. Outline-based geometric morphometric analysis to identify two Anopheles and three Culex mosquitoes in Thailand. Biodiversitas 20: 1866-1872. Geometric morphometric (GM) techniques have become popular for applications in entomology studies, especially mosquitoes. Outline-based methods (OTLs) are one such form of GM technique used to analyze pseudo-landmarks on contours or boundary outlines. This study investigated the efficacy of an OTL to distinguish two species of Anopheles mosquitoes including An. epiroticus and An. subpictus s.l. and three species of Culex mosquitoes, including Cx. quinquefasciatus, $C x$. visnui and $C x$. whitmorei in Thailand and compared outlines, including internal outline 1 (IOL1), internal outline 2 (IOL2) and external outline (EOL) within the mosquito wing to assess the optimal outline for analysis. The results indicated that OTLs were highly effective with certain species and each outline had the potential difference for identification. For size analysis, An. epiroticus had a mean perimeter length of IOL2 and EOL length larger than An. subpictus. Different sizes between species was found in IOL1, which was statistically significant after Bonferroni test $(p<0.05)$. Culex size analysis of IOL2 and EOL demonstrated a statistical difference for all species while size difference patterns between outlines found that IOL1 differed from other outlines. While shapes in two Anopheles of all cells were different between species, there was statistical significance based on Mahalanobis distances $(p<0.05)$. Almost all pairwise Mahalanobis distances between Culex species of IOL1, IOL2 and EOL established statistical differences, except for pairs of $C x$. visnui and $C x$. whitmorei via IOL2 analysis.
\end{abstract}

Keywords: Anopheles epiroticus, Anopheles subpictus s.l., Culex quinquefasciatus, Culex visnui, Culex whitmorei, geometric morphometric, outline-based method

\section{INTRODUCTION}

At present, geometric morphometric (GM) techniques have become popular based on applications in entomology studies, such as species identification, sexual dimorphism and inspection of morphological variation patterns in each different area (Lorenz et al. 2017; Chaiphongpachara 2018; Chaiphongpachara et al. 2018; Virginio et al. 2015). In recent years, its applications in biological and medical science have grown rapidly (Lorenz et al. 2017). GM is a powerful analytical tool based on the geometry of phenotype, which is commonly used to study insects, especially the family, Culicidae (Wilke et al. 2016; Dujardin 2011). Mosquitoes are one of the target insects for GM as a consequence of their wings, which are bidimensional organs suitable for GM analysis (Lorenz et al. 2017; Dujardin 2008). The main reason this technique is applied quite commonly in mosquitoes is that they are medically important insects seeing they act as vectors of human diseases (Lorenz et al. 2017). There is also the problem surrounding their identification according to the gold standard method (morphological identification by taxonomic key) - a number of species of mosquitoes have morphological similarities induced by the difficulty in controlling them.

Malaria is a life-threatening disease and one of the most severe public health problems worldwide, particularly in tropical and subtropical areas (Service 2008). Globally, the
World Health Organization (WHO) reported that there were more than two hundred million malaria cases and more than four hundred thousand deaths in 2016 (World Health Organization 2016). Malaria is caused by the protozoan parasite that belongs to the genus Plasmodium (phylum Apicomplexa) transmitted by female Anopheles mosquitoes (Diptera: Culicidae) (Cox 2010). More than 400 formally named Anopheles species have been recognized and approximately 80 species of Anopheles mosquitoes are regarded as vectors of mosquito-borne diseases (Tainchum et al. 2015). The complexity of the species of Anopheles is one of the obstacles in terms of classification. Many Anopheles species have very similar morphological characteristics that are difficult to distinguish by morphological methods (World Health Organization 2007). At present, there is an increase in the list of new species of Anopheles mosquitoes owing to the development of technology for species identification (World Health Organization 2007).

In Thailand, malaria continues to be a public health problem, especially along the international borders with Cambodia, Myanmar, and Malaysia (Parker et al. 2015). Approximately 74 species of Anopheles mosquitoes have been found distributed across different areas according to the specificity of the species in Thailand (Tainchum et al. 2015). Three species of Anopheles mosquitoes are recognized as primary malaria vectors in Thailand, including An. dirus, An. minimus, and An. maculatus 
(Parker et al. 2015). With this, three species of Anopheles have habitats in the forest areas of Thailand along the border area, corresponding to high numbers of malaria cases (Tainchum et al. 2015). An. epiroticus is considered to be a potential malaria vector and is widely distributed along the coastal areas of Thailand (Chaiphongpachara and Sumruayphol 2017). Previous research first uncovered evidence in Thailand of Plasmodium falciparum and $P$. vivax infection in An. epiroticus (Sumruayphol et al. 2010). Meanwhile, An. subpictus s.l. is a well-known vector of malaria in Indonesia and Sri Lanka but is not a vector in Thailand (World Health Organization 2007). However, unlike many countries in the Oriental region, An. subpictus s.l. is often located in coastal areas, along with the $A n$. sundaicus complex, such as An. epiroticus, causing difficulty in separating both species.

While, mosquitoes in the genus Culex are found more or less worldwide and are nocturnal vectors of many dangerous human diseases, such as Japanese encephalitis (JE) and lymphatic filariasis (LF) (Service 2008; Tolle 2009). According to the World Health Organization, there were approximately 68,000 cases of JE as a viral infection of the human brain and 13,600 to 20,400 deaths globally (World Health Organization 2014). LF (known as elephantiasis) is caused by three species of nematode worms, including Wuchereria bancrofti, Brugia malayi and B. timori, that has approximately 120 million infected cases in tropical and subtropical areas of the world (Shenoy 2008; Goel and Goel 2016). Thailand is a country located in tropical areas, and has specifically high species richness of Culex mosquito vectors with many outbreaks of Culexborne diseases. As with other genera of mosquitoes, Culex mosquitoes have a morphology similar to many other species. Therefore, finding effective alternative techniques to help classify them are important, excepting molecular techniques are powerful tools but also quite expensive.

Outline-based GM method (OTL) is a GM technique used to analyze pseudo-landmarks on contours or boundary outlines (Dujardin et al. 2014; Santillán-Guayasamín et al. 2017). Although OTL has been less popular than landmarkbased (LM) GM methods, it has outstanding potential, much more so than LM. Previous research has revealed the efficacy of OTL for Aedes mosquitoes identification in Thailand, of which OTL can better separate male Ae. albopictus and Ae. scutellaris versus LM (Sumruayphol et al. 2016). Recently, studies have demonstrated that an outline-based GM approach is highly effective in identifying certain species of Anopheles mosquitoes in Colombia (Jaramillo-O et al. 2015).

Consequently, this study investigated the efficacy of OTL in distinguishing three species of Culex mosquitoes, including $C x$. quinquefasciatus (JE and LF vectors), $C x$. visnui (JE vector) and Cx. whitmorei (LF vector) and two species of Anopheles mosquitoes (malaria vectors) including An. epiroticus and An. subpictus s.l. in Thailand. It also compared external contour and internal outlines within the mosquito wing to assess the optimal outline for analysis with OTL. The results of this research can confirm the effectiveness of OTL for identifying mosquito species with further applications in the field.

\section{MATERIALS AND METHODS}

\section{Mosquito collection and identification}

Female adults of the Culex species were collected using independent mosquito traps (Woodstream Corporation, USA) from Huay Nam Nak village $\left(13^{\circ} 22^{\prime} 36.0^{\prime \prime} \mathrm{N}\right.$, $\left.99^{\circ} 16^{\prime} 34.9^{\prime \prime} \mathrm{E}\right)$ in Ratchaburi Province, Thailand, at night (6.00 PM- 6.00 AM) during June to August 2015. Three traps were placed about five meters away from houses and inspected once a week. While, two species of Anopheles mosquitoes were collected from two areas in Thailand, including An. epiroticus from Samut Songkhram Province $\left(13^{\circ} 24^{\prime} 32.52^{\prime \prime} \mathrm{N} 100^{\circ} 0^{\prime} 41.40^{\prime \prime} \mathrm{E}\right)$ and An. subpictus s.l. from Ratchaburi Province $\left(13^{\circ} 22^{\prime} 36.0^{\prime \prime} \mathrm{N}, 99^{\circ} 16^{\prime} 34.9^{\prime \prime} \mathrm{E}\right)$ using a Mosquito Magnet Independence Mosquito Trap (Woodstream Corporation, USA). Both areas for Anopheles collection had distinct environments. Mosquito collecting areas in Samut Songkhram Province are within coastal areas, important habitats for An. epiroticus (Chaiphongpachara and Sumruayphol 2017). Although there have been reports surrounding the habitat of $A n$. subpictus s.l. in coastal areas, in Thailand, this has not been confirmed clearly, probably owing to the different species of the An. subpictus complex. Therefore, we collected $A n$. subpictus s.l. in Ratchaburi Province according to previous researchers that found them (Chaiphongpachara $\mathrm{T}$ et al. 2018). After collection, all mosquitoes were sent to the laboratory of the College of Allied Health Sciences, Suan Sunandha Rajabhat University, Samut Songkhram Provincial Education Center for species identification based on morphology using the illustrated keys to the mosquitoes of Thailand (Rattanarithikul et al. 2005a,b).

\section{Wing preparation}

Thirty samples per species of Anopheles and Culex mosquitoes were selected from the random number table. Afterward, the right wing of each female mosquito was removed from the thorax and mounted using Hoyer's medium on a microscope slide with a cover slip (if a wing was damaged, we repeated the sampling). All mosquito wings on slides were photographed under 40x magnification with a digital camera connected to a Nikon SMZ745T stereomicroscope (Nikon Corp., Tokyo, Japan) at a one-mm scale indicated on all photographs.

\section{Outline-based GM method (OTL)}

Before OTL analysis, the repeatability index as a measurement error was employed for quality estimation of a pseudo-landmarks plot (Arnqvist and Mårtensson 1998). Three outlines in Figure 1 are depicted, including internal outline 1 (IOL1), internal outline 2 (IOL2) and external outline (EOL), all considered representative in this OTL analysis. For analysis, the wing size of three outlines was assessed by the perimeter of the outlines. Meanwhile, shape variables were computed by the elliptic Fourier analysis based on perimeter coordinates of the outlines. Discriminant analysis permitted the creation of a factor map to explore the degree of wing-shape dissimilarity in each Culex and Anopheles species. 


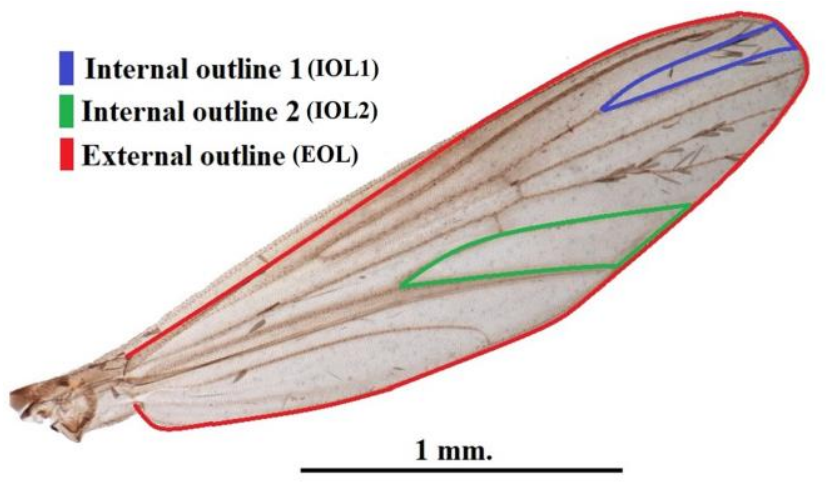

Figure 1. Three outlines for OTL analysis, including IOL1 (blue), IOL 2 (green) and EOL (red)

Further, Mahalanobis distance between species in each outline was computed using the first principal components of the normalized elliptic Fourier coefficients. A nonparametric, permutation-based test $(1,000$ cycles $)$ with Bonferroni correction was employed for statistically significant difference tests $(p<0.05)$ of the pairwise average perimeter of the outlines and Mahalanobis distance between species. The cross-validated reclassification test based on Mahalanobis distance was utilized to reclassify each individual for monitoring correctly assigned individuals.

\section{Geometric morphometric (GM) software}

Five modules of CLIC as GM software (freely available at https://xyom.io) were used for outline-based GM analysis in this study. Various modules, including the COO module for outline digitization, the TET module for editing, converting or computing data, the FOG module for processing an outline-based study (including elliptical Fourier analysis, Procrustes superimposition, principal component analyses, discriminant analyses and quantile box of size variation), the VAR module for size analysis, and the PAD module for shape analysis.

\section{RESULTS AND DISCUSSION}

The measurement errors of IOL1, IOL2 and EOL for size and outline shape estimation were low (for size $<2 \%$, $5 \%$ and $6 \%$, respectively, and $<1 \%, 4 \%$ and $5 \%$ for outline shape estimation, respectively).

\section{Anopheles species identification}

For size analysis: size variation between An. epiroticus and An. subpictus s.l. in each cell is portrayed in Figure 1. An. epiroticus had a mean perimeter length of IOL2 and EOL larger than An. subpictus s.l. (Table 1). Meanwhile, for internal cell 1, An. subpictus s.l. had a mean perimeter length that was larger than An. epiroticus. Different sizes between An. epiroticus and An. subpictus s.l. were found in IOL1, which was statistically significant after Bonferroni testing $(p<0.05)$.
For shape analysis: After principal component analysis, which showed there to be shape variations between species in each cell; factor maps from the discriminant analysis were used for evaluating group separation. In Figure 3, factor maps clearly indicate the separation between $A n$. epiroticus and An. subpictus s.l. in all cells. Meanwhile, shapes of all cells were different between species, which was statistically significant based on Mahalanobis distances (Table 2). Percentages of correct assigning of individuals from cross-validated classification tests have shown a 76$80 \%$ range for internal cell $1,63-70 \%$ range for internal cell 2 , and $63 \%$ range for external cell (Table 3 ).

\section{Culex species identification}

For size analysis: quantile boxes for comparison of mean size variation based on the perimeter of each outline are portrayed in Figure 4. In IOL1, Cx. whitmorei had the largest size while $C x$. quinquefasciatus had the smallest. In IOL2, $C x$. visnui and $C x$. whitmorei had the largest size while $C x$. quinquefasciatus had the smallest. Lastly, $C x$. visnui had the largest size while $C x$. whitmorei had the smallest for EOL. The average of the size patterns for each outline was significantly different (Table 4), such as $C x$. whitmorei differed from other species in IOL1, while in terms of both different outlines, all Culex species varied ( $p$ $>0.05$, Table 4).

For shape analysis: the factor maps of the discriminant analysis of wing shape based on each outline indicated Culex species separation that was not clearly distinguishable between species (Figure 5).

All pairwise interspecific comparisons of shape between species based on Mahalanobis distance were significant in IOL1 and EOL, while for IOL2, only $C x$. whitmore $i$ was different from other species $(p<0.05$, Table $5)$. For comparisons of the range of cross-validated classification scores between outlines, EOL was greater than IOL1 and IOL2 (63-83\% VS 46-63\% and 50-60\%, respectively, Table 6 ).

Table 1. Statistical analyses of mean perimeter length in each cell of Anopheles epiroticus and An. subpictus s.l.

\begin{tabular}{lccc}
\hline \multirow{2}{*}{$\begin{array}{l}\text { Anopheles } \\
\text { species }\end{array}$} & \multicolumn{3}{c}{ Mean \pm Standard deviation $(\mathbf{m m})$} \\
\cline { 2 - 4 } An. epiroticus & IOL1 & IOL2 & EOL \\
An. subpictus s.l. & $1.59 \pm 0.02^{\mathrm{a}}$ & $2.52 \pm 0.03^{\mathrm{a}}$ & $6.16 \pm 0.14^{\mathrm{a}}$ \\
\hline
\end{tabular}

Note: In each row, different superscript letters indicate statistical differences at $p<0.05$

Table 2. Comparisons of shape differences between Anopheles epiroticus and An. subpictus s.l. based on Mahalanobis distances in each cell

\begin{tabular}{lcc}
\hline Cells & $\begin{array}{c}\text { Mahalanobis } \\
\text { distances scores } \\
\text { between species }\end{array}$ & $\boldsymbol{p}$-values \\
\hline IOL1 & 2.50 & $<0.001^{* *}$ \\
IOL2 & 2.17 & $0.021^{*}$ \\
EOL & 2.92 & $0.002^{* *}$ \\
\hline
\end{tabular}

Note: * indicates significant differences at $p<0.05$ and ** indicates significant differences at $p<0.01$ 
Table 3. Cross-validated classification of Anopheles epiroticus and An. subpictus s.l. based on shape in each cell

\begin{tabular}{llll}
\hline \multirow{2}{*}{ Anopheles species } & \multicolumn{3}{c}{$\begin{array}{c}\text { Percentages of correct assigning of } \\
\text { individuals (assigned/observed) }\end{array}$} \\
\cline { 2 - 4 } & IOL1 & \multicolumn{1}{c}{ IOL2 } & EOL \\
\hline & & & \\
An. epiroticus & $76(23 / 30)$ & $63(19 / 30)$ & $63(19 / 30)$ \\
An. subpictus s.1. & $80(24 / 30)$ & $70(21 / 30)$ & $63(19 / 30)$ \\
\hline
\end{tabular}

Table 4. Statistical analyses of mean perimeter length in each cell of Culex quinquefasciatus, Cx.visnui and Cx. whitmorei

\begin{tabular}{lccc}
\hline \multirow{2}{*}{ Culex species } & \multicolumn{3}{c}{$\begin{array}{c}\text { Mean values of size and standard } \\
\text { deviation }(\mathbf{m m})\end{array}$} \\
\cline { 2 - 4 } & IOL1 & IOL2 & EOL \\
\hline & & & \\
Cx.quinquefasciatus & $1.70 \pm 0.03^{\mathrm{a}}$ & $2.37 \pm 0.06^{\mathrm{a}}$ & $6.22-0.53^{\mathrm{a}}$ \\
Cx. visnui & $1.78 \pm 0.02^{\mathrm{a}}$ & $2.45 \pm 0.05^{\mathrm{b}}$ & $6.29-0.27^{\mathrm{b}}$ \\
Cx. whitmorei $^{\mathrm{c}}$ & $1.82 \pm 0.01^{\mathrm{b}}$ & $2.45 \pm 0.01^{\mathrm{c}}$ & $6.10-0.90^{\mathrm{c}}$
\end{tabular}

In each row, different superscript letters indicate statistical differences at $p<0.05$.
Table 5. Statistical differences in Mahalanobis distance between Culex species in each outline

\begin{tabular}{llccc}
\hline $\begin{array}{c}\text { Out- } \\
\text { lines }\end{array}$ & \multicolumn{1}{c}{ Species } & $\begin{array}{c}\text { Cx. } \\
\text { quinquefascia } \\
\text { tus }\end{array}$ & $\begin{array}{c}\text { Cx. } \\
\text { visnui }\end{array}$ & $\begin{array}{c}\text { Cx. } \\
\text { whitmorei }\end{array}$ \\
\hline IOL1 & $\begin{array}{l}\text { Cx. quinquefasciatus } \\
\text { Cx. visnui }\end{array}$ & - & & \\
& Cx. whitmorei & $1.88^{*}$ & - & \\
IOL2 & Cx. quinquefasciatus & $2.02^{*}$ & $2.07^{*}$ & - \\
& Cx. visnui & - & & \\
& Cx. whitmorei & $2.83^{*}$ & - & \\
EOL & Cx. quinquefasciatus & $-7^{*}$ & 1.92 & - \\
& Cx. visnui & $2.81^{*}$ & - & \\
& Cx. whitmorei & $3.57^{*}$ & $3.85^{*}$ & - \\
\hline
\end{tabular}

Note: $*=$ Statistical differences

Table 6. Cross-validated classification scores of three species of Culex mosquitoes in each outline

\begin{tabular}{lccc}
\hline \multirow{2}{*}{ Culex species } & \multicolumn{3}{c}{$\begin{array}{c}\text { Percent correctly assigned individuals } \\
\text { (assigned/observed) }\end{array}$} \\
\cline { 2 - 4 } & IOL1 & IOL2 & EOL \\
\hline Cx. quinquefasciatus & $46(14 / 30)$ & $50(15 / 30)$ & $63(19 / 30)$ \\
Cx. visnui & $50(15 / 30)$ & $56(17 / 30)$ & $70(21 / 30)$ \\
Cx. whitmorei & $63(19 / 30)$ & $60(18 / 30)$ & $83(25 / 30)$ \\
\hline
\end{tabular}

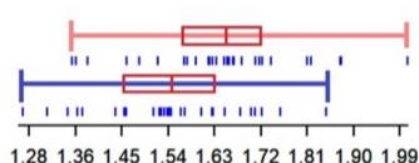

A

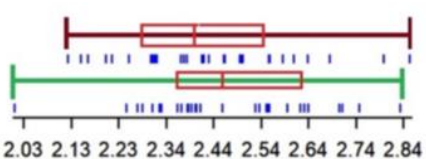

B

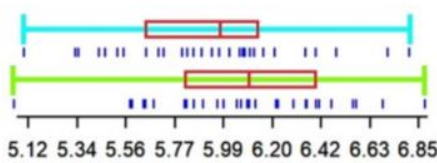

C

Figure 2. Comparisons of size variation (in $\mathrm{mm}$ ) between species Anopheles in each cell, including: A. IOL1, B. IOL2, C. EOL. Each quantile box shows the group median that separates the 25th and 75th quartiles. Vertical bars under the boxes represent the wing sizes of individual mosquitoes.

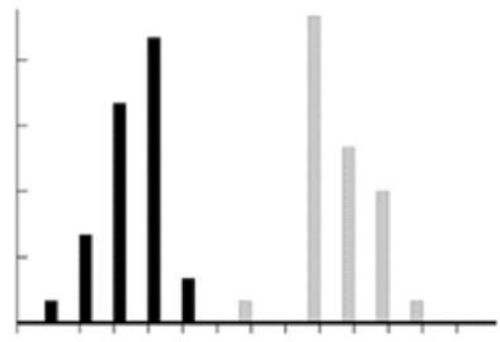

Black = Group $130: 14101320000000$ White $=$ Group 2 30:0000010148610

A

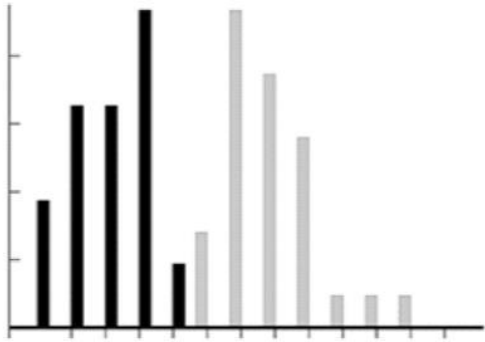

Black $=$ Group $130: 4771020000000$ White = Group 2 30:0000310861110 B
An. subpictus s.l. An. epiroticus

Figure 3. Factor maps of the two discriminant factors derived from shape variables for Anopheles epiroticus (black) and An. subpictus s.l. (grey) in each cell, including: A. IOL1, B. IOL2, C. EOL 


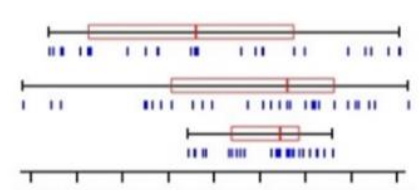

1.401 .481 .551 .621 .691 .771 .841 .911 .98

A

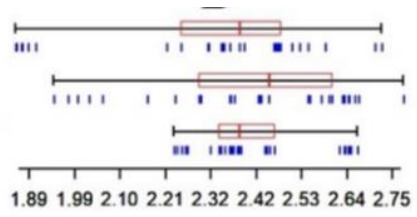

B

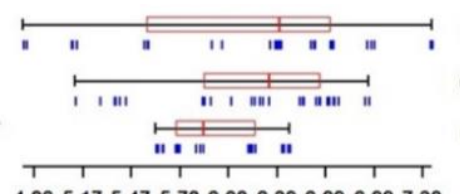

4.865 .175 .475 .786 .086 .396 .696 .997 .30

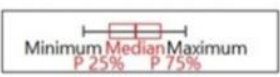

C

Figure 4. Wing perimeter variation between Culex species (mm) from OTL analysis with IOL1 (A), IOL2 (B) and EOL (C). Each quantile box features the group median expressed as median with the 25th and 75th quartiles. Vertical bars under the boxes represent the perimeter sizes of the individual sample

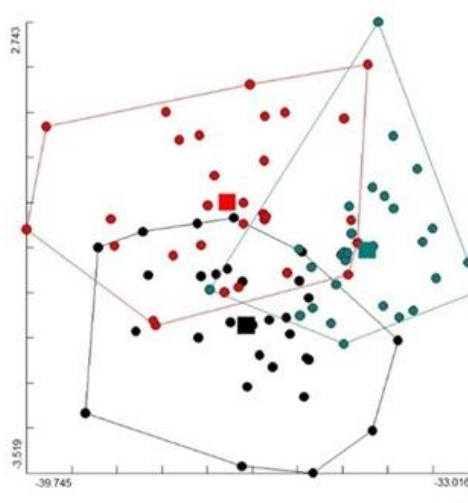

A

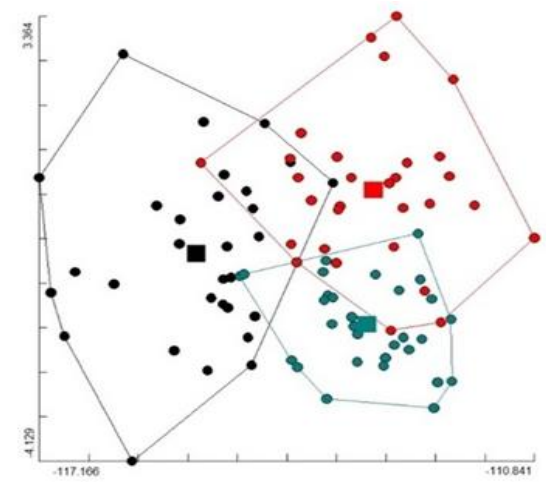

Cx.quinquefasciatus

B

Cx.quinquefasciatus

Cx.visnui

Cx. whitmorei

Figure 5. Factor maps of the two discriminant factors (DFs; horizontal axis is the first DF, vertical axis is the second DF) derived from shape variables of the Culex species, of which each point represents an individual (A: IOL1, B: IOL2, C: EOL)

\section{Discussion}

This research tested the efficiency of discrimination between three Culex species, including $C x$. quinquefasciatus, $C x$. visnui, and $C x$. whitmorei, and two Anopheles species including An. epiroticus and An. subpictus s.l. in Thailand using an outline-based GM approach. The results of the study revealed the potential for discrimination of Culex and Anopheles mosquitoes but there was a difference between each cell for outline-based GM analysis.

\section{Anopheles epiroticus and An. subpictus s.l.}

Through size analysis, differences between Anopheles species were found in IOL1, while size differences were not found in IOL2 and EOL. The difference of shape between mosquitos species in each cell may emanates from the specificity between species of mosquitoes with internal and external cells of wings. Previous research has compared two GM methods, including landmark-based and outline-based GM approaches for identification of mosquito vectors in Ratchaburi Province, Thailand, and the results of size analysis revealed that both methods are different (Chaiphongpachara 2018). This clearly indicates that even though it is the same wing, the different positions of the analysis can affect the results of the size between species. However, the size factor is not more important than the shape factor for species identification (Dujardin 2008; Dujardin 2011). In general, the size of adult mosquitoes is often the result of the influence of the environment on the habitat of the larval stage, such as temperature and food quality (Lorenz et al. 2017).

The shape of the wings is popularly used in GM analysis to establish species of mosquito vectors because they are expressed from genetics that is specific to the species (Louise et al. 2015; Lorenz et al. 2017). Shape analysis has demonstrated differences between species in all cells, reflecting the effectiveness of the method for discrimination between both mosquitoes. In accordance with previous research, an outline-based GM approach has proven effective in species identification of many arthropods, such as mosquitoes (Sumruayphol et al. 2016), trombiculid mites within the genus Walchia (Sungvornyothin et al. 2018), stomoxys flies (Changbunjong et al. 2016), and tsetse flies (Kaba et al. 2017). These results suggest that each outline on the same wing of a mosquito has the power to discriminate each 
species of mosquitoes differently. Cross-validated classification scores revealed that IOL1 is most effective for discrimination between An. epiroticus and $A n$. subpictus s.1., followed by IOL2 and EOL, respectively. This corresponds to the results of size analysis, which indicates that IOL1 exhibits statistical differences in size

\section{Culex quinquefasciatus, $C x$. visnui, and $C x$. whitmore}

Size analysis of IOL2 and EOL exhibited statistical differences for all species while size difference patterns between outlines determined that IOL1 differed from other outlines. In addition, the mean perimeter between Culex spp. was different for each outline. This revealed that the outline position affected the results from the size analysis, which may be different when using varied outlines for OTL analysis, even in the same set. Certain outlines are not strong representatives for definition when estimating the total size of mosquito wings. However, size is not a factor for species classification owing to variation occurring readily (De Carvalho et al. 2017; Dujardin 2008; Hidalgo et al. 2015).

Overall, shape analysis of OTL uncovered the effects of the three Culex species. Almost all pairwise Mahalanobis distances between species of IOL1, IOL2, and EOL established statistical differences based on non-parametric permutation tests, except for the pair of $C x$. visnui and $C x$. whitmorei with the IOL2 analysis. This research was consistent with previous studies conducted in terms of species identification of Aedes, Culex, and Anopheles mosquitoes in Thailand, which found that OTL was a potential technique (Chaiphongpachara 2018). Comparison of the efficiency of each outline for species separation via cross-validated classification scores established that EOL had the highest potential, especially for $C x$. whitmorei as a LF vector. This corresponds to previous research where the application of EOL and IOL for testing separation of 11 Anopheles species in Colombia determined that both outlines had different results (Jaramillo-O et al. 2015).

In conclusion, an outline-based GM approach is one of the reliable GM approaches for discriminating mosquito species based on the different analysis of contours or an internal cell of the wing between species. This research has shown the efficiency of discrimination between three Culex and two Anopheles mosquitoes in Thailand using a GM approach. In addition, the results also indicate that IOL1 is the most suitable position for discriminating both species of Anopheles mosquitoes. While, EOL is more effective for species separation than IOL across all three Culex species. The results of this study are a guide to the use of an outline-based GM approach to solve the morphological similarities between species of mosquito further.

\section{ACKNOWLEDGEMENTS}

I extend sincere appreciation to the College of Allied Health Sciences, Suan Sunandha Rajabhat University, Samut Songkhram Provincial Education Center, Thailand for its support of this research.

\section{REFERENCES}

Arnqvist G, Mårtensson T. 1998. Measurement error in geometric morphometrics: Empirical strategies to assess and reduce its impact on measures of shape. Acta Zool Acad Sci H 44 (1-2): 73-96.

Chaiphongpachara T. 2018. Comparison of Landmark- and Outline-based geometric morphometrics for discriminating mosquito vectors in Ratchaburi Province, Thailand. BioMed Res Intl. DOI: $10.1155 / 2018 / 6170502$

Chaiphongpachara T, Sumruayphol S. 2017. Species diversity and distribution of mosquito vectors in coastal habitats of Samut Songkhram province, Thailand. Trop Biomed 34 (3): 524-532.

Chaiphongpachara T, Juijayen N, Chansukh KK. 2018. Wing geometry analysis of Aedes aegypti (Diptera, Culicidae), a dengue virus vector, from multiple geographical locations of Samut Songkhram, Thailand. J Arthropod Borne Dis 12: 351-360.

Changbunjong T, Sumruayphol S, Weluwanarak T, Ruangsittichai J. 2016. Landmark and outline-based geometric morphometrics analysis of three Stomoxys (Diptera: Muscidae). Folia Parasitol. DOI: 10.14411/fp.2016.037.

Cox FE. 2010. History of the discovery of the malaria parasites and their vectors. Parasit Vector 3 (1): 5.

De Carvalho GC, Vendrami DP, Marrelli MT, Wilke ABB. 2017. Wing variation in Culex nigripalpus (Diptera: Culicidae) in urban parks. Parasit Vectors 10 (1): 22-26.

Dujardin JP. 2008. Morphometrics applied to medical entomology. Infect Genet Evol 8 (6): 875-890.

Dujardin JP. 2011. Modern Morphometrics of medically important insects. In: Tibayrenc M (ed.). Genetics and Evolution of Infectious Diseases. Elsevier; Burlington.

Dujardin JP, Kaba D, Solano P, Dupraz M, McCoy KD, Jaramillo-O N. 2014. Outline-based morphometrics, an overlooked method in arthropod studies. Infect Genet Evol 28: 704-714.

Goel TC, Goel A. 2016. Lymphatic filariasis. Springer. Singapore.

Hidalgo K, Dujardin JP, Mouline K, Dabiré RK, Renault D, Simard F. 2015. Seasonal variation in wing size and shape between geographic populations of the malaria vector, Anopheles coluzzii in Burkina Faso (West Africa). Acta Trop 143: 79-88.

Jaramillo-O N, Dujardin JP, Calle-Londoo D, Fonseca-Gonzalez I. 2015. Geometric morphometrics for the taxonomy of 11 species of Anopheles (Nyssorhynchus) mosquitoes. Med Vet Entomol 29 (1): 26-36.

Kaba D, Berté D, Ta BTD, Tellería J, Solano P, Dujardin JP. 2017. The wing venation patterns to identify single tsetse flies. Infect Genet Evol 47: 132-139.

Lorenz C, Almeida F, Almeida-Lopes F, Louise C, Pereira SN, Petersen V, Suesdek L. 2017. Geometric morphometrics in mosquitoes: What has been measured. Infect Genet Evol 54: 205-215.

Louise C, Vidal PO, Suesdek L. 2015. Microevolution of Aedes aegypti. PLoS ONE 10 (9): e0137851. DOI: 10.1371/journal.pone.0137851.

Parker DM, Carrara VI, Pukrittayakamee S, McGready R Nosten FH. 2015. Malaria ecology along the Thailand-Myanmar border. Malar J 14 (1): 388

Rattanarithikul R, Harbach RE, Harrison BA, Panthusiri P, Jones JW Coleman RE. 2005. Illustrated keys to the mosquitoes of Thailand. II. Genera Culex and Lutzia. SE Asian J Trop Med 2: 1-97.

Rattanarithikul R, Harrison BA, Pantusiri P, Coleman RE. 2005. Illustrated keys to the mosquitoes of Thailand. SE Asian J Trop Med 1: $1-80$.

Santillán-Guayasamín S, Villacís AG, Grijalva MJ, Dujardin JP. 2017. The modern morphometric approach to identify eggs of Triatominae. Parasit Vectors 10: 55.

Service M. 2008. Medical entomology for students. 4th ed. Cambridge University Press. Liverpool, England.

Shenoy RK. 2008. Clinical and pathological aspects of filarial lymphedema and its management. Korean J Parasitol 46 (3): 119-125.

Sumruayphol S, Apiwathnasorn C, Komalamisra N, Ruangsittichai J, Samung Y, Chavalitshewinkoon-Petmitr P. 2010. Bionomic status of Anopheles epiroticus Linton \& Harbach, a coastal malaria vector, in Rayong Province, Thailand. Southeast Asian J Trop Med Public Health 41 (3): 541-547.

Sumruayphol S, Apiwathnasorn C, Ruangsittichai J, Sriwichai P, Attrapadung S, Samung Y, Dujardin JP. 2016. DNA barcoding and wing morphometrics to distinguish three Aedes vectors in Thailand. Acta Trop 159: 1-10. 
Sungvornyothin S, Kumlert R, Paris DH, Prasartvit A, Sonthayanon P, Apiwathnasorn C, Morand S, Stekolnikov AA. 2018. Ticks and tickborne diseases geometric morphometrics of the scutum for di ff erentiation of trombiculid mites within the Genus Walchia (Acariformes: Prostigmata: Trombiculidae), a probable vector of scrub typhus. Ticks Tick Borne Dis 10 (2): 495-503.

Tainchum K, Kongmee M, Manguin S, Bangs MJ, Chareonviriyaphap T. 2015. Anopheles species diversity and distribution of the malaria vectors of Thailand. Trends Parasitol 31 (3): 109-119.

Tolle MA. 2009. Mosquito-borne Diseases. Curr Probl Pediatr Adolesc Health Care 39 (4): 97-140.
Virginio F, Oliveira Vidal P, Suesdek L. 2015. Wing sexual dimorphism of pathogen-vector culicids. Parasit Vectors 8: 159.

Wilke ABB, De Oliveira Christe R, Multini LC, Vidal PO, Wilk-Da-silva R, De Carvalho GC, Marrelli MT. 2016. Morphometric wing characters as a tool for mosquito identification. PLoS ONE 11 (8): e0161643. DOI: 10.1371/journal.pone.0161643.

World Health Organization. 2007. Anopheline species complexes in South and South-east Asia. World Health Organization, Geneva.

World Health Organization. 2014. WHO Factsheet Vector-borne diseases. Factsheet Number. 387 (5): 10. World Health Organization, Geneva.

World Health Organization. (2016). World malaria report 2016. World Health Organization, Geneva. DOI: 10.1071/EC12504. 